\title{
Cerebral Microbleeds
}

\section{Serebral Mikrokanamalar}

Keywords: Cerebral microbleeds, amyloid burden, amyloid PET, cerebral amyloid angiopathy

Anahtar Kelimeler: Serebral mikrokanamalar, amiloid yükü, amiloid PET, serebral amiloid anjiyopati

\section{Cerebral Microbleeds}

Cerebral microbleeds (CMBs) detected in hemosiderinsensitive cranial magnetic resonance imaging (MRI) is a common cerebrovascular pathology, which is a risk factor for intracerebral hemorrhage and ischemic stroke in the elderly population. CMBs seen in lobar localization are associated with cerebral amyloid angiopathy (CAA), and those in deep localization are more associated with hypertensive arteriopathy. Population-based studies previously conducted on this subject are limited. GraffRadford et al. (1) compared the prevalence of CMBs in the normal population and the relationship with beta amyloid burden in positron emission tomography (PET) in their paper published last year in the Journal of Neurology.

For the study, participants without cognitive impairment were randomly selected from among participants of the Mayo Clinic Study of Aging. 3T cranial MRI including T2 gradient echo (GRE)-weighted images was taken for the selected 1215 participants, and 1213 of them underwent amyloid PET imaging and were analyzed.

As a result, the age range of the participants was 60-98 years, the mean age was 74.1 years; $53 \%$ were male. The mean age was older (78.7 vs. 72.8 years, $\mathrm{p}<0.001)$, male sex $[183(67 \%)$ vs. $465(49 \%), \mathrm{p}<0.001]$ and hypertension were more frequent [208 $(76 \%)$ vs. $587(62 \%), \mathrm{p}<0.001]$, and amyloid PET involvement was higher $[1.68(0.48)$ vs. CMBs $1.52(0.37), \mathrm{p}<0.001]$ in participants with $\mathrm{CMBs}$ than in those without CMBs. Participants with $\mathrm{CMBs}$ were more likely to develop dementia than those without CMBs [9 (3\%) vs. $7(1 \%), \mathrm{p}=0.001]$.
It was observed that the frequency of $\mathrm{CMBs}$ was $23 \%$ in all groups, and increased with age to $39 \%$ above 80 years of age.

According to their location, there was only a significant relationship between amyloid PET involvement and the presence of lobar CMBs, but not deep/infratentorial CMBs. In patients with amyloid involvement without lobar CMBs, the etiology was observed to be associated with hypertension. CMBs were more frequently seen in the parietal, occipital, and temporal lobes.

The association of CMBs with age, sex, hypertension, and amyloid load was shown, but no association of CMBs with ApoE $\varepsilon 4$ carrier, dyslipidemia, smoking, and diabetes mellitus was found.

This study expanded the findings of previous populationbased studies, showing a relationship between global amyloid load and the location of CMBs, and suggested a different underlying pathophysiology for CMBs depending on location. It revealed that there was a relationship between regional lobar amyloid burden and regional CMBs, and the presence of two or more CMBs in temporal, occipital, parietal regions and amyloid burden.

Considering that approximately $37 \%$ of patients over eighty years of age have atrial fibrillation, the risk of ischemic stroke, which is an indication of anticoagulation, increases and the number of CMBs associated with amyloid load increases with age. The fact that CMBs constitute a strong risk factor for hemorrhagic stroke also poses a challenge in management in terms of safety of anticoagulation in these patients.

The fact that amyloid load in patients with Alzheimer's dementia or vascular cognitive impairment is also associated only with lober $\mathrm{CMBs}$ supports the view that CAA causes lober CMBs.

Address for Correspondence/Yazışma Adresi: Çă̆la Akı MD, Istanbul University, Istanbul Faculty of Medicine, Department of Neurology, Istanbul, Turkey Phone: +905386440065 E-mail: aki.cagla@gmail.com ORCID: orcid.org/0000-0001-6950-7406

Received/Geliş Tarihi: 03.03.2019 Accepted/Kabul Tarihi: 05.03.2019

${ }^{\circ}$ Copyright 2019 by Turkish Neurological Society

Turkish Journal of Neurology published by Galenos Publishing House. 
In a research group, patients receiving anti-amyloid therapies for Alzheimer's disease were observed to develop new CMBs, and there was an association with the presence of the ApoE $\varepsilon 4$ allele and amyloid load.

The fact that hypertension is associated with lobar CMBs among patients who are amyloid negative suggests that amyloid PET can help distinguish between the underlying mechanisms.

The amyloid load in the temporal, parietal, and occipital regions is associated with two or more CMBs, and these regions have a high rate of CAA in autopsy. Therefore, intracerebral bleeding due to CAA occurs more frequently in the temporal and occipital lobes.

Having a large population-based sample size is the strength of this study. The limitations of the study are that the data are cross-sectional and that susceptibility-weighted imaging is more sensitive than GRE.
Consequently, in this population-based study, it was observed that the frequency of CMBs increased with age and that amyloid load was associated with increased frequency of lobar CMBs. The study is important in terms of guiding for identifying individuals at risk of intracerebral bleeding or complications originating from anti-amyloid therapy.

\section{Ethics}

Peer-review: Internally peer-reviewed.

Financial Disclosure: The author declared that this study received no financial support.

\section{Reference}

1. Graff-Radford J, Botha H, Rabinstein AA, et al. Cerebral microbleeds: prevalence and relationship to amyloid burden. Neurology 2019;92:e253-e262. 